\title{
First report of Serotype-1 Marek's disease virus (MDV-1) with oncogenic form in backyard turkeys in Turkey: a molecular analysis study
}

\author{
Hasan Ongor ${ }^{{ }^{*}} \mathbb{D}$, Necati Timurkaan ${ }^{2}$, Hasan Abayli ${ }^{3}$, Burak Karabulut ${ }^{2}$, Hakan Kalender ${ }^{1}$, Sukru Tonbak ${ }^{3}$, \\ Hatice Eroksuz ${ }^{2}$ and Burhan Çetinkaya ${ }^{1}$
}

\begin{abstract}
Background: Marek's disease (MD) is a lymphoproliferative disease caused by Gallid alphaherpesvirus 2 (GaHV-2, MDV-1), which primarily affects chickens. However, the virus is also able to induce tumors and polyneuritis in turkeys, albeit less frequently than in chickens.

Results: This is the first study in Turkey reporting the molecular characterization of a MDV-1 strain detected in a flock of backyard turkeys exhibiting visceral lymphoma. Here, MEQ, vIL-8, pp38 and 132-bp tandem repeat regions, which are frequently preferred in the pathotyping of MDV-1, were examined. It was determined that the MEQ gene of MDV-1/TR-21/turkey strain obtained in the present study encoded 339 amino acids (1020 nt) and had four proline-rich repeat regions (PPPP). Based on the nucleotide sequence of the MEQ gene of the MDV-1/TR-21/turkey strain, a phylogenetic tree was created using the MEGA-X software with the Maximum Likelihood Method (in 1000 replicates). Our strain was highly identical (> 99.8) to the Italian/Ck/625/16, Polish (Polen5) and some Turkish (LayerGaHV-2-02-TR-2017, Tr/MDV-1/19) MDV-1 strains. Also, nt and aa sequences of the MEQ gene of our strain were 99.1 and $99.41 \%$ identical to another Turkish strain (MDV/Tur/2019) originated from chickens. Sequence analysis of pp38 and $v / L-8$ genes also supported the above finding. The identity ratios of nucleotide and amino acid sequences of $v / L-8$ and pp38 genes of MDV-1/TR-21/turkey strain were $99.64-100 \%$ and $99.79-100 \%$, respectively, when compared with those of the Polish strain. According to 132-bp tandem repeat PCR results, the MDV-1/TR-21/turkey strain had five copies.
\end{abstract}

Conclusions: These results suggested that the MDV-1/TR-21/turkey strain obtained from backyard turkeys can be either very virulent or very virulent plus pathotype, though experimental inoculation is required for precise pathotyping.

Keywords: Turkeys, MDV-1, MEQ, pp38, vIL-8, 132-bp tandem repeats

\section{Background}

Marek's disease (MD) is a common lymphoproliferative and neuropathic disease of chickens, and occasionally of turkeys, quails and geese caused by gallid

\footnotetext{
*Correspondence: hongor@firat.edu.tr

1 Department of Microbiology, Faculty of Veterinary Medicine, Firat University, 23110 Elazig, Turkey

Full list of author information is available at the end of the article
}

alphaherpesvirus 2 (GaHV-2). However, reports of MD in turkeys are increasing worldwide in the last few years. The etiological agent, commonly known as Marek's disease virus (MDV) is a member of the genus Mardivirus, sub-family Alfaherpesvirinae in family Herpesviridae. MDVs are classified into three different species which correspond to previously described serotypes: GaHV-2 (serotype 1- MDV-1), GaHV-3 (serotype 2MDV-2) and meleagrid alphaherpesvirus 1 (MeHV-1) or 
herpesvirus of turkeys (HVT) (serotype 3) [1-3]. There is also an additional classification for serotype $1 / \mathrm{MDV}-1$ that divides the viruses into four pathotypes that is based on virulence in chickens in vaccination challenge studies: the mild $(\mathrm{m})$, virulent $(\mathrm{v})$, very virulent $(\mathrm{vv})$ and very virulent plus (vv+) forms [4]. This method is time consuming, expensive and requires many chickens of a specific genetic type and MD-antibody status. Serotype 1 (MDV1) includes all the virulent strains and some attenuated vaccine strains and, only viruses in this serotype are able to cause the disease in chickens.

MDV is oncogenic in chickens and clinical signs include immunosuppression, polyneuritis and T-cell lymphoma formation in the visceral and ectoderm-derived tissues. Although the virus can also induce tumors in turkeys, more frequently detected oncogenic agents in this species include the reticuloendotheliosis virus (REV), avian sarcoma leukosis virus (ASLV) and the lymphoproliferative disease virus (LPDV) MD is a major threat for the poultry industry because of the economic consequences in the absence of efficient control strategies [1]. Vaccination with non-oncogenic HVT, MDV serotype 2 (MDV-2) or attenuated MDV-1 vaccines is frequently used for the control of the disease in chickens [5]. On the other hand, turkeys are rarely vaccinated against MD. Although MD vaccines have successfully been used in reducing major losses due to the disease, several factors such as improper use of the vaccine, exposure to virulent viruses before the development of immunity, interference from maternally derived antibodies and emergence of new virulent strains have limited the effectiveness of the vaccines. In fact, MDV has evolved into a more virulent form and the emerging strains not only are capable of breaking vaccine immunity but also show immunosuppressive effects $[6,7]$.

The MDV genome contains more than 200 genes and among these genes, Marek's EcoRI-Q (MEQ), phosphoprotein-38 ( $p p 38)$ and viral interleukin $8(v I L-8)$ have been reported to play important role in the virulence of MDV-1 [7, 8]. The MEQ gene encodes a 339-amino acid protein with an $\mathrm{N}$-terminal basic region leucine zipper (bZIP) domain and a C-terminal transactivation domain. The bZIP domain, similar to that of the Jun/Fos family of oncoprotein, consists of two stretches of basic residues basic regions 1 and 2 (BR1 and BR2) and a leucine zipper. The transactivation domain is characterized by 2.5 proline-rich repeats (PRRs), which contain several SH3binding motifs [9]. The $M E Q$ gene is regarded as one of the principle oncogene of MDV-1 and also contributes to immunosuppression. This gene plays a key role in the transformation process of latently-infected $\mathrm{T}$ lymphocytes. Since MDV-2 and HVT viruses do not carry the $M E Q$ gene, they are considered as avirulent and generally used in the preparation of effective vaccines [10]. The pp38 gene is responsible for inhibiting the maturation of lymphocytes and for cytolytic replication [3]. The vIL-8 gene, a viral chemokine, ensures early cytolytic infection and latency [7].

BamHI-H is a transcriptionally active region [11], and it was suggested that the loss of oncogenicity associated with 132-bp expansion could be due to a direct effect on the BamHI-H gene family transcripts. When MDV is attenuated by continuous cell culture, the copy number of 132-bp repeats in BamHI-H region often increases from two to more than 20 copies [12]. Therefore, the 132bp of the MDV-1 genome can also be used as an important PCR target gene to differentiate the field MDV strain from the vaccine strain [13].

Various methods such as virus isolation, pathology and immunohistochemistry that have advantages and disadvantages over each other have been used in the diagnosis of MD. By the means of molecular based methods such as PCR and real-time PCR (qPCR), it is possible to obtain a good indication of pathotype/virulence of the virus owing to the amplification of oncogenicity/pathogenicity related genes followed by sequencing. This also enables us to better understand why protection is not provided in some vaccinated flocks and then develop more efficient vaccines containing the correct pathotype based on molecular characterization [14]. The PCR analysis of the BamH1-H and BamH1-D regions of the viral genome flanking the 132-bp tandem repeat region is an important criterion that can be used to distinguish between pathogenic and non-pathogenic strains of MDV-1. Although there is a paucity of information on the relationship between the number of 132-bp tandem repeats and pathogenicity of virus strains in turkeys, it has been reported that only one or two repeats of the 132-bp region were present in the most pathogenic strains of MDV in chickens [5].

This study was carried out to investigate the molecular characteristics of $M E Q, p p 38, v I L-8$ genes and BamH1-H and BamH1-D regions of the viral genome flanking the 132-bp tandem repeat region in the field strain originated from visceral tumors and feather tips of turkeys by polymerase chain reaction (PCR). In addition, the amplified products were subjected to sequencing in order to determine pathotype of the field strain and construct a phylogenetic tree.

\section{Results}

\section{Gross and histopathological findings}

Liver and spleen were enlarged in both animals necropsied, with multifocal, nodular structures of varying sizes (Fig. 1A, B). It was also noted that the glandular stomach was thickened in one of the turkeys as well as 


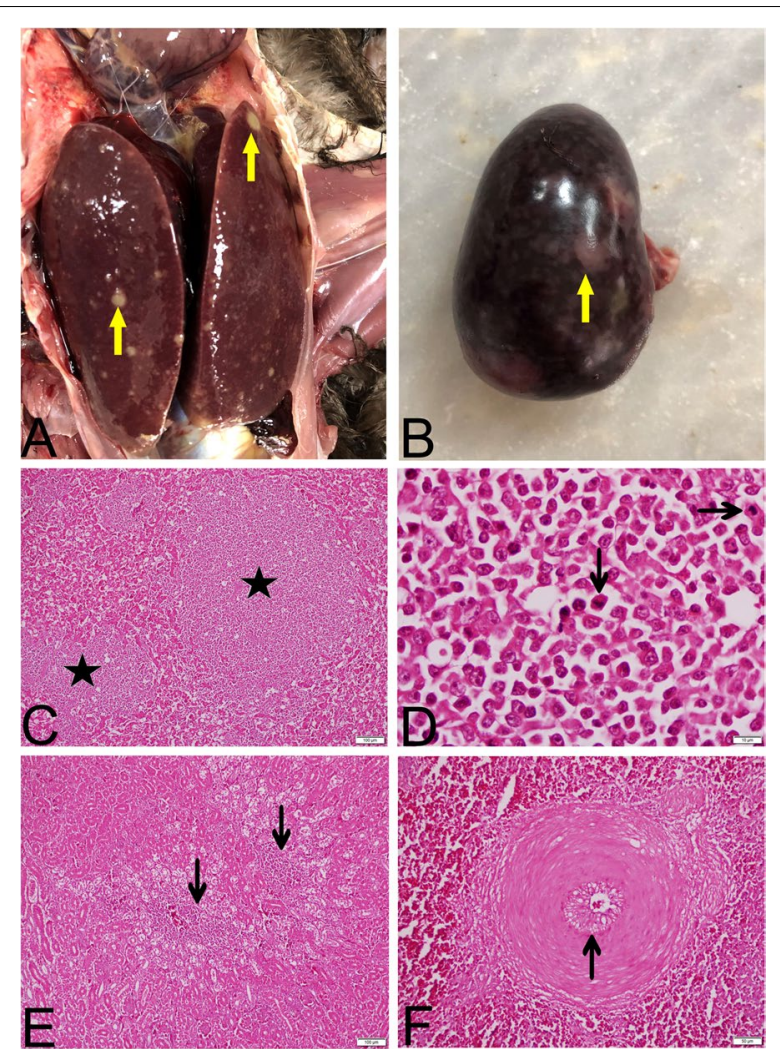

Fig. 1 Liver (A) and spleen (B) enlarged and multifocal nodules of varying size (arrows). Liver sections (C and D) showing nodular structures (stars) consisting of atypical and pleomorphic lymphoid cells with numerous mitotic figures (arrows) in hepatic parenchyma and decreasing amount of hepatocytes. Kidney section (E), tumor cells (arrows) between the renal tubules and glomeruli. Spleen section (F), an artery showing atherosclerosis (arrow). (C: 100X, D:1000X, E:100X, F:400X)

enlargement in the regional lymphoid structures of the intestines.

In the histopathological examination, pleomorphic lymphoproliferative foci of varying size were observed in the liver (Fig. 1C), spleen, lungs (in both animals), heart, kidneys, proventriculus, and intestines (in one animal). These cells were detected to be atypical and, pleomorphic lymphoblasts and lymphocytes. The tumor cells displayed marked mitotic figures ( $>8$ per high-power fields) (Fig. 1D). Tumor cells were found to be located multifocally in areas, ranging from small foci to nodular structures in the liver, lungs and spleen. In the liver, tumor cells were also found intensively in the sinusoids. Tumor cells were located especially in the portal areas in one of the turkeys. It was observed that the normal histological structure of the liver was impaired and the number of hepatocytes was considerably reduced. Tumor cells were found between the muscle fibers in the heart, especially around the veins, between the renal tubules and glomeruli in the kidney (Fig. 1E) and in the propria mucosa in the proventriculus and intestines. Mild edema and lymphocytic infiltration were noticed in the ischiadic nerve in both animals, but no tumor cells were observed. In addition, atherosclerosis characterized with arterial lipid accumulation in the intima and luminal narrowing was detected in the arteries of the spleen in one case (Fig. 1F).

\section{Analysis of the MEQ gene}

Following PCR combined with $M E Q$ primers, the amplification product of approximately $1050 \mathrm{bp}$ in length was detected on the agarose gel. As a result of bidirectional sequencing of the purified PCR product, the $M E Q$ gene (1020 nt in length) encoding 339 aa was detected. According to BLAST search, the nucleotide sequence of the $M E Q$ gene was similar (up to $99.9 \%$ ) to the MDV-1 strains in the GenBank. The strain obtained in the study was named as MDV-1/TR-21/turkey and the $M E Q$ gene sequence was submitted to the GenBank Nucleotide Sequence Database under the accession number OK322357. Table 1 presents detailed information on MDV-1 strains selected from GenBank with different pathotypes originated from different regions. MDV-1/ TR-21/turkey strain and some Turkish (Layer-GaHV-202-TR-2017 and TrMDV-1/19), Italian (GaHV-2/Italy/ Turkey/601/16 and GaHV-2/Italy) The /Ck/625/16), and Polish (Polen5) MDV-1 strains were in the same cluster in the phylogenetic tree, which were highly identical (>99.8\%). The nt and aa sequences of the $M E Q$ gene of our strain were 99.1 and $99.41 \%$ identical to another Turkish strain originated from chickens (MDV/ Tur/2019), while 99.93 and $99.76 \%$ similarities were determined between our strain and the Italian turkey strain (GaHV-2/Italy/Turkey/601/16), respectively.

The $M E Q$ of our strain was detected to have four proline-rich repeat regions (PPPP). The start of PPPPs in the $M E Q$ gene was based on amino acid positions 152, 175, 191 and 232. It was found that another PPPP starting at position 216 of the $M E Q$ was disrupted due to substitution at amino acid position 218 (P to $\mathrm{S}$ ). The amino acid substitutions detected between the MEQs of MDV-1/ TR-21/turkey and some other MDV-1 strains after multiple alignment are shown in Table 2. The aa substitutions of the MEQ of MDV-1/TR-21/turkey were as follows: 77 ( $\mathrm{K}$ to $\mathrm{E}$ ), 80 (D to $\mathrm{Y}$ ), 88 ( $\mathrm{T}$ to $\mathrm{A}$ ), 93 ( $\mathrm{R}$ to $\mathrm{Q}$ ), 110 (C to $\mathrm{S}$ ), 115 (L to V), 119 ( $\mathrm{R}$ to $\mathrm{C}$ ), 139 (A to T), 153 (Q to $\mathrm{P}$ ), 176 (A to P), 180 (A to T), 217 (A to P), 218 (P to S), 277 (P to $\mathrm{L}$ ), 283 (V to $\mathrm{A}$ ), 315 ( $\mathrm{S}$ to $\mathrm{W}$ ) and 320 (T/N to I).

\section{Analysis of the vIL-8 and $p p 38$ genes}

Following PCR combined with primers specific for $v I L-8$ and $p p 38$ gene, amplification products at approximately 
Table 1 Details of the MDV-1 strains, retrieved from GenBank, which were used for the phylogenetic analysis

\begin{tabular}{|c|c|c|c|c|c|c|c|c|}
\hline GaHV-2 strain & Country & Year & Pathotype & Size & PPPPs & Host & Accession number & References \\
\hline CVI988 & Netherlands & 1969 & Att & 398 & 7 & NA & DQ530348 & {$[15]$} \\
\hline 814 & China & 1986 & att & 398 & 7 & Chicken & $J F 742597$ & {$[16]$} \\
\hline 3004 & Russia & NA & att & 398 & 7 & NA & EU032468 & NA \\
\hline $\mathrm{CU}-2$ & USA & 1970 & $\mathrm{~m}$ & 398 & 7 & Gallus gallus & AY362708 & {$[17]$} \\
\hline MD70/13 & Hungary & 1970 & v & 339 & 5 & Gallus gallus & MF431495 & [18] \\
\hline $617 A$ & USA & 1993 & $v$ & 339 & 4 & NA & AY362712 & {$[17]$} \\
\hline 04CRE & Australia & 2004 & $v$ & 398 & 5 & NA & EF523773 & [19] \\
\hline EU-1 & Italy & 1992 & vV & 339 & 5 & Gallus gallus & MF431494 & [18] \\
\hline MD5 & USA & 1977 & vv & 339 & 4 & NA & AF243438 & [7] \\
\hline Woodlands1 & Australia & 1992 & vv & 339 & 5 & NA & EF523775 & [19] \\
\hline RB1B & USA & NA & vV & 339 & 5 & NA & AY243332 & [17] \\
\hline $648 \mathrm{~A}$ & USA & 1994 & $v v+$ & 339 & 2 & NA & AY362725 & [17] \\
\hline New & USA & 1999 & $v v+$ & 339 & 2 & NA & AY362719 & {$[17]$} \\
\hline W & USA & 1999 & $v v+$ & 339 & 4 & NA & AY362723 & {$[17]$} \\
\hline ATE2539 & Hungary & 2000 & $\mathrm{vv}+$ & 339 & 5 & Gallus gallus & MF431493 & {$[18]$} \\
\hline Polen5 & Poland & 2010 & $v v+$ & 339 & 4 & Gallus gallus & MF431496 & [20] \\
\hline Tn-n1 & India & 2012 & NA & 339 & 5 & Gallus gallus domesticus & HM749324 & NA \\
\hline UDEACO & Colombia & 2013 & NA & 339 & 2 & Gallus gallus breed layer & KU058701 & [21] \\
\hline GaHV-2/Italy/Ck/507/15 & Italy & 2015 & NA & 418 & 9 & backyard chicken & MK139661 & [22] \\
\hline GaHV-2/Italy/Ck/625/16 & Italy & 2016 & NA & 339 & 4 & backyard chicken & MK139666 & {$[22]$} \\
\hline Layer-GaHV-2-02-TR-2017 & Turkey & 2017 & NA & 339 & 4 & layer chicken & MN045205 & [23] \\
\hline MDV/Tur/2019 & Turkey & 2019 & High oncogenity & 339 & 5 & cochin chicken & MN956505 & [24] \\
\hline TrMDV1/19 & Turkey & 2019 & NA & 339 & 4 & commercial chicken & MN817545 & {$[25]$} \\
\hline GaHV-2/Italy/Turkey/601/16 & Italia & 2016 & NA & 339 & 4 & meat type turkey & MN017102 & [22] \\
\hline MDV-1/TR-21/turkey & Turkey & 2021 & - & 339 & 4 & backyard turkey & OK322357 & in this study \\
\hline
\end{tabular}

$900 \mathrm{bp}$ and $1000 \mathrm{bp}$ lengths were obtained, respectively. Of these, 887 and $1006 \mathrm{bp}$ lengths were associated with MDV-1 in the BLAST search. The $v I L-8$ gene of MDV-1/ TR-21/turkey was highly identical (nt 99.65\%, aa 100\%) to Chinese (mg432607), Polish (Polen5), Italian (EU-1) and Hungarian ATE2539 strains. Similarly, the pp38 gene of the MDV-1/TR-21/turkey strain was highly identical (nt 99.7\%, aa 100\%) to Italian (EU-1), Turkish (MDV/ Tur/2019), Polish (Polen5), Hungarian (MD70/13 and ATE2539), American (CU-2) and Chinese (MG432697 and 814) strains.

The sequence data of the $v I L-8$ and pp38 genes of the MDV-1/TR-21/turkey strain were submitted to the GenBank Nucleotide Sequence Database under the accession numbers OK322358 and OK322359, respectively.

\section{Analysis of 132-bp tandem repeats}

Following PCR combined with primers specific for 132bp tandem repeats, $830 \mathrm{bp}$ amplification product was obtained on agarose gel. According to the results, the MDV-1/TR-21/turkey strain had five copies of the 132bp tandem repeats.
Agarose gel analysis of PCR amplification results for $M E Q, p p 38, v I L-8$, and 132-bp tandem repeats of MDV-1 and REV was shown in Fig. 2. No positive results were obtained in the PCR analysis for REV.

\section{Discussion}

In spite of the fact that MD is rarely seen in turkeys, it has been reported in some countries including Netherlands, France, the UK, Israel, Germany, Scotland, Egypt and the USA $[14,22,26,27]$. Severe outbreaks of the disease have been reported in commercial turkey flocks in Europe and Israel between 1997 and 2002 [1, 28]. In some of these outbreaks, the affected turkey flocks were observed to be raised in proximity to broiler chickens. High mortality rates ranging from 40 to $80 \%$ have been noted in some countries $[1,28]$. In the USA, the presence of MD in turkeys was first reported by Hauck et al. [29] who detected MDV-1 in house-type and zooraised turkeys based on both immunohistochemical and molecular methods. In Turkey, first cases of MD in turkeys have been reported in 2020 based on pathological and immunohistochemical analyses [30]. The turkey is the natural host of HVT and the virus can circulate 
Table 2 Amino acid substitutions in MEQ oncoprotein of the Turkish strains and the reference strains

\begin{tabular}{|c|c|c|c|c|c|c|c|c|c|c|c|c|c|c|c|c|c|}
\hline \multirow[t]{2}{*}{ (Pathotypes) Strain/isolates } & \multicolumn{2}{|c|}{$\begin{array}{l}\text { Basic } \\
\text { region }\end{array}$} & \multicolumn{3}{|c|}{ Leucine Zipper } & \multirow[b]{2}{*}{115} & \multirow[b]{2}{*}{119} & \multicolumn{9}{|c|}{ Repression/Transactivation domain } & \multirow[b]{2}{*}{320} \\
\hline & 77 & 80 & 88 & 93 & 110 & & & 139 & $\begin{array}{l}153 \\
\text { PPPP }\end{array}$ & $\begin{array}{l}176 \\
\text { PPPPP }\end{array}$ & 180 & 217 & $\begin{array}{l}218 \\
\text { PPPP }\end{array}$ & 277 & 283 & 315 & \\
\hline MDV-1/TR-21/turkey & E & Y & $A$ & Q & $\mathrm{S}$ & V & C & $\mathrm{T}$ & $\underline{p}$ & $\underline{P}$ & $\mathrm{~T}$ & $P$ & S & L & A & W & । \\
\hline (v)MD70/13 & K & $\mathrm{D}$ & . & & C & . & . & . & . & . & . & . & $\underline{P}$ & . & . & S & . \\
\hline (v)617A & . & . & . & . & C & . & $\mathrm{R}$ & . & 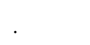 & & & $A$ & $\underline{p}$ & . & . & S & \\
\hline$(\mathrm{vv}) \mathrm{Md} 5$ & K & D & . & & C & . & . & . & . & . & . & A & $\underline{p}$ & . & V & S & $\mathrm{T}$ \\
\hline$(\mathrm{vv}) \mathrm{RB} 1 \mathrm{~B}$ & K & $\mathrm{D}$ & . & & $C$ & . & . & & . & . & . & . & $\underline{P}$ & . & . & S & . \\
\hline$(v v+) 648 A$ & K & $\mathrm{D}$ & & . & $C$ & & $\mathrm{R}$ & . & Q & A & A & A & $\underline{P}$ & $P$ & & S & \\
\hline$(v v+) \mathrm{New}$ & K & $\mathrm{D}$ & & . & C & . & $\mathrm{R}$ & . & Q & A & . & $A$ & $\underline{P}$ & . & V & S & $\mathrm{T}$ \\
\hline$(v v+) W$ & K & $\mathrm{D}$ & . & & $C$ & . & . & & . & 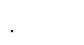 & . & $A$ & $\underline{P}$ & . & V & S & $\mathrm{T}$ \\
\hline$(\mathrm{vv}+)$ ATE2539 & . & . & $\mathrm{T}$ & $\mathrm{R}$ & C & . & . & A & . & & & . & $\underline{P}$ & 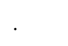 & . & S & . \\
\hline$(v v+)$ Polen5 & . & . & . & . & . & . & . & . & . & & . & . & $=$ & . & . & S & . \\
\hline GaHV-2/Italy/Ck/625/16 & . & . & . & . & . & . & . & . & . & & - & . & $=$ & . & . & s & . \\
\hline Layer-GaHV-2-02-TR-2017 & . & . & . & & . & . & . & & . & - & . & & $=$ & . & . & - & - \\
\hline MDV/Tur/2019 & & . & $\mathrm{T}$ & $\mathrm{R}$ & C & $L$ & . & A & . & . & . & . & $\underline{P}$ & . & . & S & . \\
\hline TrMDV1/19 & & & & . & & & & . & & & & . & & & & S & $\mathrm{N}$ \\
\hline GaHV-2/Italy/Turkey/601/16 & . & . & . & & . & . & . & & . & . & . & . & . & . & . & S & $\cdot$ \\
\hline
\end{tabular}

Pathotypes of virulent MDV; $v M D V$, very virulent $M D V ; \mathrm{vvMDV}$, very virulent plus $M D V ; \mathrm{vv}+\mathrm{MDV}$

".'.' mean same to the consensus amino acids below corresponding sites

"-" mean lacking of consensus amino acids below corresponding sites

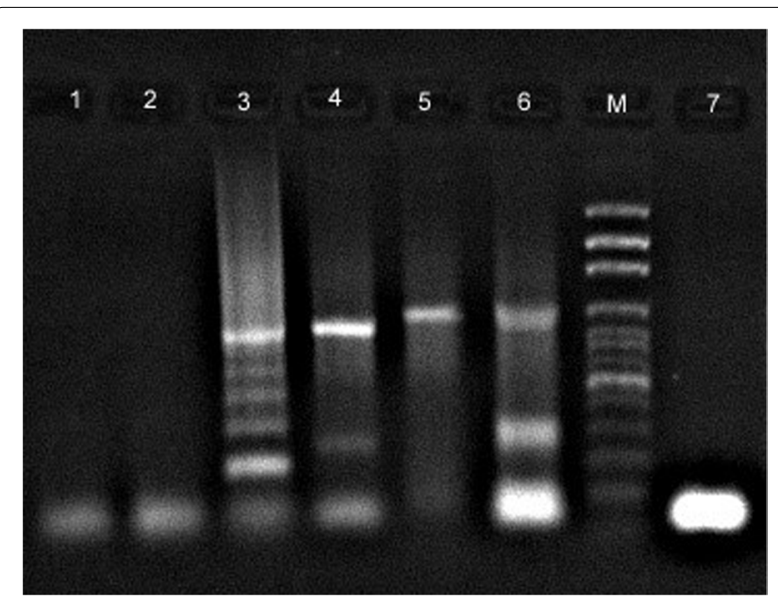

Fig. 2 Agarose gel electrophoresis (1.5 W/v) of PCR products of MDV-1 and REV. M; 100 bp DNA ladder (Solis BioDyne, USA). Lane 1-2; Negative controls for MDV and REV, respectively, PCR amplification of 132-bp tandem repeats (Lane-3; 830 bp), pp38 (Lane 4; 887 bp), v/L-8 (Lane-5; 1006 bp), MEQ (Lane-6; 1020 bp), and REV (Lane-7)

in turkey populations without causing disease [31]. The fact that turkeys are not frequently infected with MDV has been explained with genetic resistance and widespread presence of HVT which could provide some protection against the disease. However, detection of highly oncogenic MDV-1 in HVT-vaccinated turkeys in an experimental study casts doubt on this view [32].

Gross and histopathological findings observed in the current study were mostly compatible with previously reported MD cases in avian species [1,30]. As an interesting finding, atherosclerosis that was detected in an artery of spleen in one turkey has also been noted in both natural and experimental MD infections of chickens [33-35], though its pathogenesis is yet to be clarified. In a study conducted by Reddy et al. [27], very virulent MDV strain was detected in the cytological and histopathological examination of lymphomas in the internal organs of vaccinated turkey flocks, though the type of the vaccine was not indicated. It has therefore been reported that vaccination of turkeys may not protect them against increasingly virulent field strains of MDV [27]. However, it should be underlined that false positive results might have been obtained from cytological and histopathological examinations, and detection of the pathotype by using molecular tools can produce more accurate results [36]. It was suggested that apart from in vivo pathotyping assays on susceptible chickens [4], molecular sequencing is one of the most suitable method for exact classification of MDV-1 strains.

The nucleotide-based classification of MDV virulence based on their $M E Q$ gene is highly advantageous when compared to the classical gold standard method 
of pathotype determination. The great divergence of the $M E Q$ gene sequences enabled Shamblin et al. [17] to characterize distinctive polymorphisms and point mutations that correlated with the virus virulence. Previous reports have suggested that the most virulent MDV strains contain the lowest (2-5) number of PPPP repeats in the $M E Q$ gene, while the low-pathogenicity and/or attenuated MDV strains show the highest (7-8) number of PPPP repeats $[17,19,22]$. In the sequence analysis of the $M E Q$ gene, four PPPP repeats were detected in the present study. In addition, the detection of a disruption at one of the PPPP repeats due to substitution at amino acid position 218 ( $\mathrm{P}$ to $\mathrm{S}$ ) suggested that the MDV-1 strain obtained here could belong to $\mathrm{vv}$ or vv + pathotype.

The $M E Q$ gene of MDV-1/TR-21/turkey was highly identical to the Italian strain GaHV-2/Italy/Turkey/601/16, but unlike the Italian strain, our strain had an amino acid substitution at position 315 (S to W) of the $M E Q$. The MDV-1/TR-21/turkey strain and other MDV-1 strains reported in commercial and layer chickens in Turkey were also similar in character and contain several aa substitutions in the $M E Q$ gene (S315W and N320I) [23-25]. Our strain was $99.8 \%$ identical to another Turkish Layer-GaHV-2-02-TR-2017 strain based on the data of partial $M E Q$. Controversial opinions have been put forward about horizontal transmission between turkeys and chickens. Although some MD cases in commercial turkey flocks have been linked with the contamination originated from chickens, it has been reported that the epidemiological role of chickens might be limited $[22,28,29,37]$. In this study, the high genetic similarity detected between our turkey strain and other strains derived from chickens may be an important indicator for interspecies transmission. On the other hand, the turkeys sampled here were originated from a house type flock which also included chickens, and although there was no information about the vaccination history in this flocks, no disease was observed in the chickens. In this case, it is plausible to suggest that our MDV strain adapted to turkeys. All in all, large scaled studies are needed to have a better understanding of the epidemiology of MDV-1 infection in turkeys.

In addition to $M E Q$ gene, molecular investigation of other virulence associated markers such as $p p 38$ and $v I L$ 8 plays important role in the detection of pathotype of MDV- 1 . The results of $v I L-8$ gene and $p p 38$ gene analysis were consistent with those of $M E Q$ and showed high similarity to Polish (Polen5), Italian (EU-1) and Hungarian ATE2539 strains. Some researchers have previously reported that the repeat numbers of BamH1-H and BamH1-D may also be important in the pathotyping of MDV-1 [5, 25]. The 132-bp repeat numbers have been reported to be only one or two in the most pathogenic strains of MDV-1, while six or seven in mild pathogenic strains in chickens [21]. In this study, we found that our strain had five copies of 132-bp tandem repeats. Although this seems to conflict with the previous reports for $M E Q$ analysis which is frequently used for pathotyping, it is not possible to make a precise comparison because no data are available for 132-bp tandem repeats in turkeys. Also, the number of 132-bp tandem repeats may not have an absolute link to virulence.

In the last decade, the $\mathrm{vv}$ + pathotype of MDV-1 has been reported to be predominant $[16,17,38]$ that may explain why the disease occurred in vaccinated chicken flocks. Previous studies conducted in our country have also revealed the presence of MDV-1 field isolates (pathotype $\mathrm{vv}+$ ) in vaccinated chickens with disease manifestations $[24,25]$. Very virulent (vv) and vv + pathotypes of MDV-1 frequently induce higher mortality and more visceral lymphomas, and have the tendency to more frequently break through genetic host resistance or immunity induced by vaccination.

The newly emerging variants and increase in oncogenicity/pathogenicity of MDV due to the consistent changes in the virus cause significant economic losses in poultry. This feature of the MDV may also lead to the insufficient protection of the vaccines. Today, field strains of MDV have been shown to be highly infectious and might cause disease in vaccinated flocks $[23,25]$. It has been reported that HVT vaccine did not show protection against MDV-1 virulent pathotypes in turkeys, but vaccination with prototype CVI988 vaccine (Rispens) has successfully been used against these pathotypes in France and Switzerland [28]. However, some studies failed to show this protection [32]. It is therefore crucial to develop more effective vaccines against the disease.

\section{Conclusions}

Although the number of MD cases in turkeys is increasing in the world, there is a paucity of sequence data for MDV-1 in this species in the GenBank. The current study was the first in our country that indicated the pathotype of the virus isolated from turkeys by detecting the significant markers using molecularV tools. $M E Q$, pp38 and $v I L-8$ gene data of MDV-1/TR-21/turkey strain obtained from backyard turkeys here will contribute to the knowledge on host distribution and molecular epidemiology of MDV-1. It was concluded that vaccine selections should be based on the determination of pathotype of the field MDV-1 isolates by molecular tools. Although vaccination against MD is applied regularly in chickens due to significant economic losses, it is not widely used in turkeys because of low incidence. The results of 
Table 3 Primers used for detection and identification of MDV and REV

\begin{tabular}{|c|c|c|c|}
\hline Virus/Gene & Primer sequence $\left(5^{\prime}-3^{\prime}\right)$ & Amplicon size & References \\
\hline$M E Q$ & $\begin{array}{l}\text { ATGTCTCAGGAGCCAGAGCCGGCGCT } \\
\text { GGGGCATAGACGATGTGCTGCTGAG }\end{array}$ & $\begin{array}{l}1062 \\
(1242)\end{array}$ & {$[40]$} \\
\hline pp38 & $\begin{array}{l}\text { TCATCTTCAACCCACAGCCATCC } \\
\text { TCGCTTAATCTCCGCCTCCAAC }\end{array}$ & 1006 & [13] \\
\hline$V / L-8$ & $\begin{array}{l}\text { GAGACCCAATAACAGGGAAATC } \\
\text { TAGACCGTATCCCTGCTCCATC }\end{array}$ & 887 & \\
\hline 132-bp repeat & $\begin{array}{l}\text { ATGCGATGAAAGTGCTATGGAG } \\
\text { ATCCCTATGAGAAAGCGCTTGA }\end{array}$ & Variable & \\
\hline REV & $\begin{array}{l}\text { GAAGCAGACAATAGGACTGG } \\
\text { TTGACCTAGGGTATCCATCTC }\end{array}$ & 850 & [39] \\
\hline
\end{tabular}

the present study suggested that vaccination in turkeys against MDV, which is oncogenic and highly virulent, could be considered in both Turkey and other countries as well as good management practices and efficient biosafety measures.

\section{Materials and methods}

Sample history and processing

Two dead six-month-old turkeys (Bourbon red strain) from a flock with the complaints of loss of appetite, inability to stand up, diarrhea and death within 1

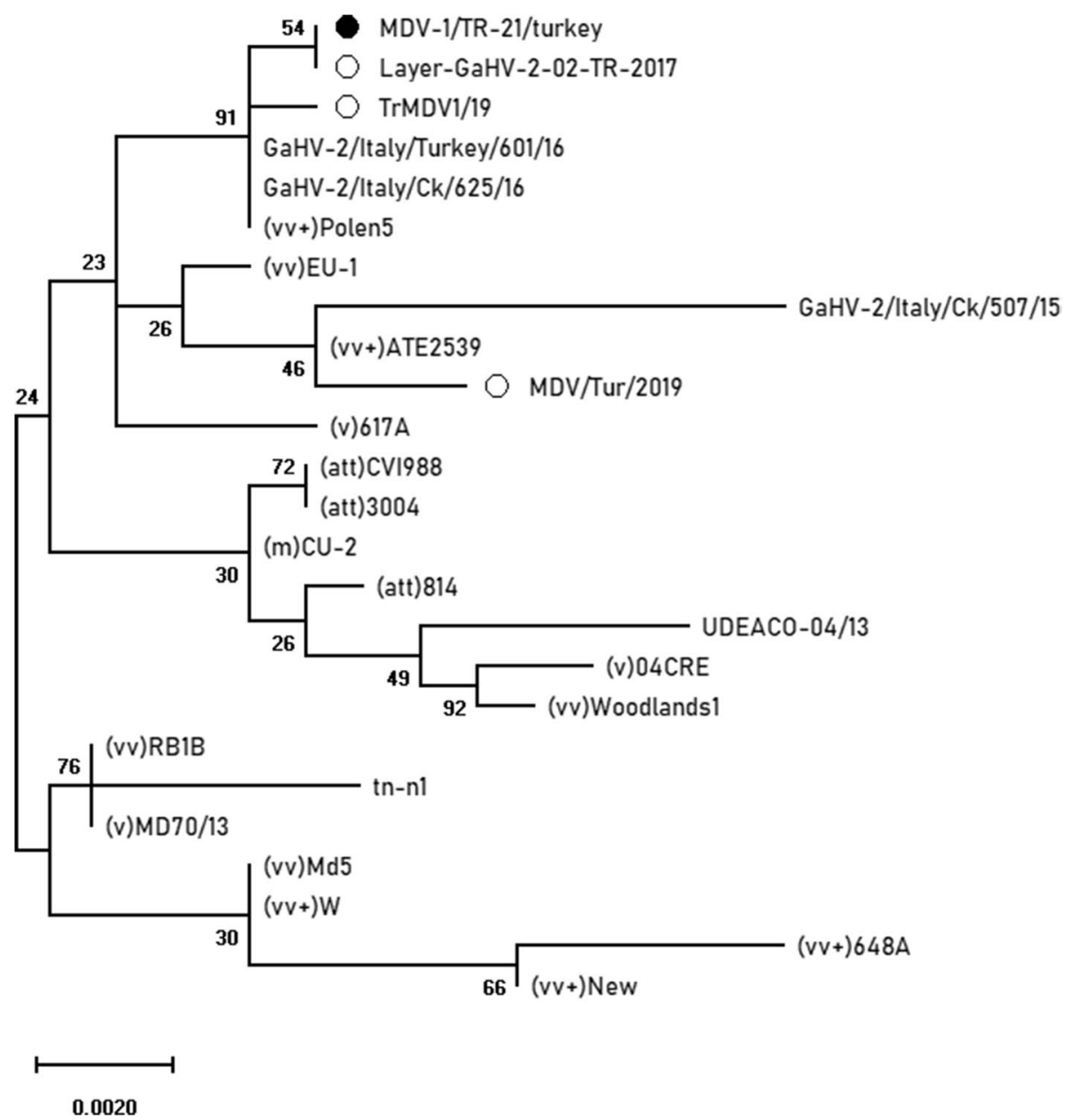

Fig. 3 Phylogenetic analysis of the MEQ gene of MDVs. Phylogenetic trees were created using the Maximum Likelihood method (1000 replicates) and Tamura Nei model by the Mega X. Filled circles represent the Turkish MDV strain obtained from this study, while the unfilled circles represent other Turkish MDV strains 


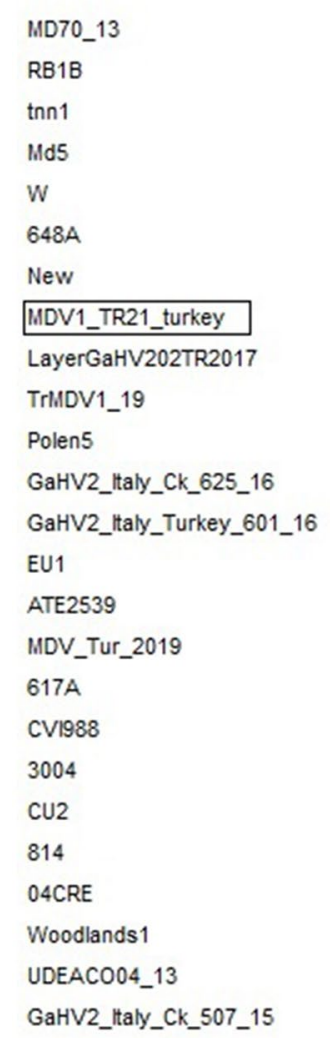
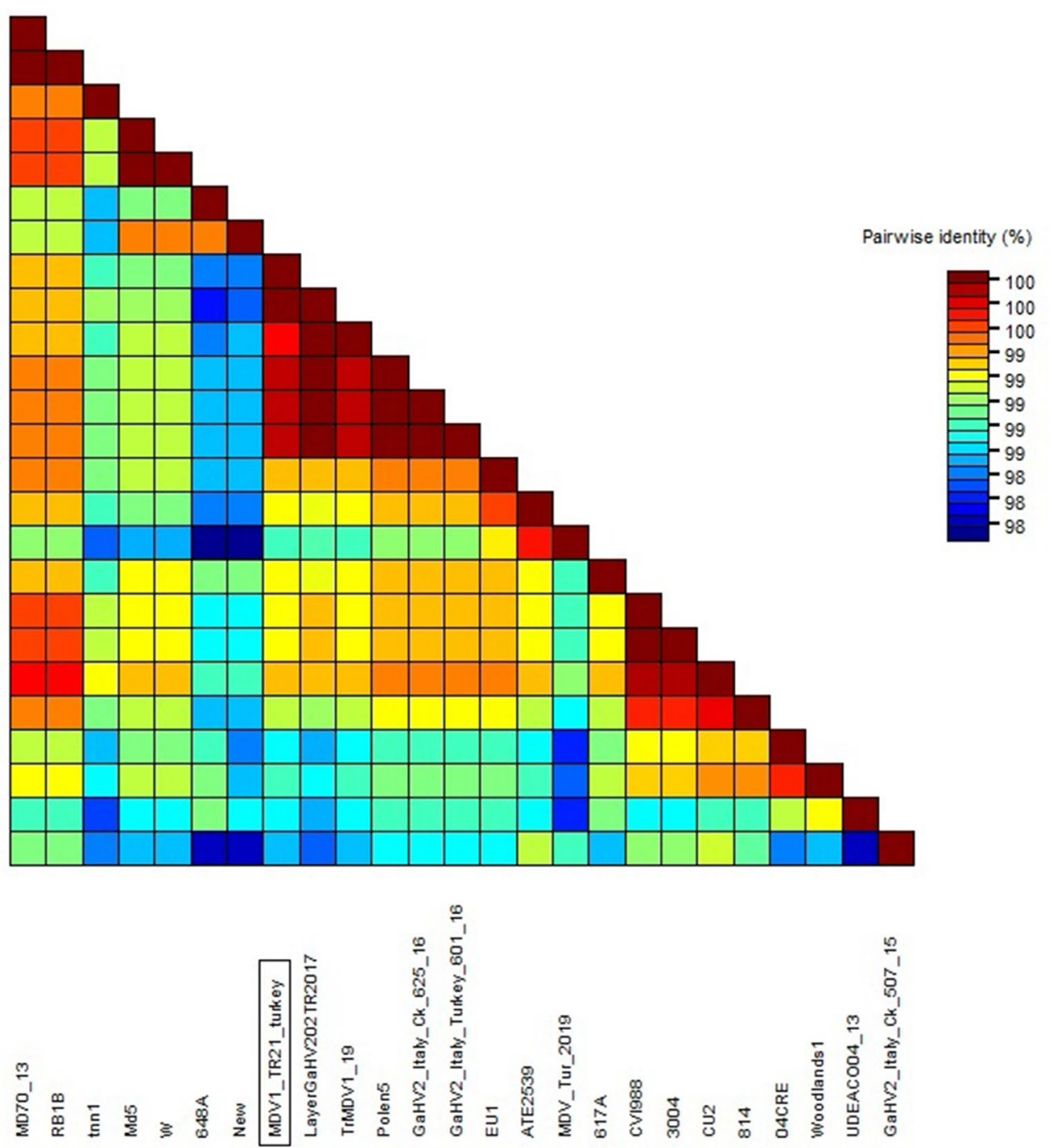

Fig. 4 Pairwise identity analysis on nucleotide sequencing of the MEQ gene of MDV strains obtained from this study and selected from GenBank

week were submitted to the Veterinary Faculty of Firat University located in the east of Turkey. The turkeys belonged to a small family type flock (the capacity was 30 animals in total) which also included chickens. However, no disease symptoms were noted in chickens. Systemic necropsy was performed, and tissue (liver, spleen, lungs, heart, kidneys, brain, eyes, proventriculus and intestines) specimens were fixed in the $10 \%$ neutral formalin solution, and placed in standard tissue processing cassettes. After routine tissue processing and paraffin embedding procedures, histological sections were taken from the paraffin blocks with a rotary microtome, stained with hematoxylin eosin, and examined under light microscopy.

\section{Virological analysis}

Tumor-bearing organs of turkeys collected at necropsy were aliquoted for virological examinations and stored at $-20^{\circ} \mathrm{C}$. Sections from tumor-bearing organs (liver and kidney) and feather tips were homogenized in $1 \mathrm{X}$ phosphate-buffered saline (PBS, pH 7.2-7.4). The resulting homogenate was centrifuged at $1500 \mathrm{x} g$ for $15 \mathrm{~min}$. DNA-RNA isolation from the supernatant was performed with the QIAamp MinElute Virus Spin kit (Qiagen, Hildeni Germany) according to the manufacturer's instructions. Extracted nucleic acids were eluted in $50 \mu \mathrm{L}$ of elution buffer, quantified in a spectrophotometer (Nanodrop 2000, Thermo Fisher, MA, USA) and kept at $-20^{\circ} \mathrm{C}$ until analysis. 


\section{Detection of REV and MDV}

For the detection of REV, we followed the polymerase chain reaction (PCR) procedure described by Ongor and Bulut [39]. Specific $M E Q$ [23] and 132-bp repeat primers [13] were used to detect MDV, another oncogenic virus. The DNA template was then used for amplification of the $p p 38$ and $v I L-8$ regions of MDV [13]. The PCR procedure applied in the reference for diagnosis and identification of MDV was followed without modification. The obtained amplicons were analyzed by electrophoresis $(110 \mathrm{~V} / 40 \mathrm{~min})$ in $1.5 \%(\mathrm{w} / \mathrm{v})$ agarose-TAE $(40 \mathrm{mM}$ Trisacetate, $\mathrm{pH}$ 8.0, $1 \mathrm{mM}$ EDTA) gel stained with ethidium bromide. The sequences of primer sets selected for this study are shown in Table 3.

\section{Sequencing and phylogenetic analysis}

PCR products were gel purified and sequenced in a commercial sequencing service (Macrogen Europe, Amsterdam, The Netherlands). This stage was performed in an ABI Prism 3130 genetic analyzer (Applied Biosystems), using the BigDye Terminator v3.1cycle sequencing kit (ApApplied Biosystems). Bidirectional nucleotide sequences aligned by Clustal W software was edited, verified with BLAST (BLAST: Basic Local Alignment Search Tool (nih.gov) and submitted to the GenBank database. Then, nucleotide sequence data of MDV strain obtained from this study and other strains selected from GenBank were transferred to Mega X software [41]. Aligned nucleotide sequences were converted to amino acids and compared with each other. Also, using the aligned nucleotide sequences, a phylogenetic tree for $M E Q$ gene was constructed with MEGA X software (Fig. 3). At this stage, Maximum Likelihood method and Tamura Nei model with 1000 bootstrap replicates were used [42]. The pairwise identity of the multiple aligned sequences was calculated using Sequence Demarcation Tool Version 1.2 (SDTv1.2) [43] and the graph was drawn according to the phylogenetics generated by the Neighbor joining method. The MDV-1 strains in Table 1 were used when constructing the phylogenetic tree and calculating sequence pairwise identity (Fig. 4).

\begin{abstract}
Abbreviations
MD: Marek's disease; MDV: Marek's disease virus; GaHV: Gallid alphaherpesvirus; ASLV: Avian sarcoma leucosis virus; HVT: Turkey herpesvirus; REV: Reticuloendotheliosis virus; LPDV: Lymphoproliferative disease virus; MEQ: Marek's EcoRI-Q-encoded protein; PP38: Phosphoprotein-38; vIL-8: Viral interleukin 8; PPPP: Four proline molecules.
\end{abstract}

\section{Acknowledgements}

Not applicable.

\section{Authors' contributions}

$\mathrm{HO}$ and NT designed the study; HE and BK participated in necropsies and histopathological analyses. HA and ST performed virological analysis. BC and
HK wrote the manuscript. All authors read and approved the last version of the manuscript.

Funding

Not applicable.

Availability of data and materials

The datasets used and/or analyzed during the current study are available from the corresponding author on reasonable request.

\section{Declarations}

Ethics approval and consent to participate

Not applicable.

Consent for publication

Not applicable.

Competing interests

The authors declare that they have no competing interests.

\section{Author details}

${ }^{1}$ Department of Microbiology, Faculty of Veterinary Medicine, Firat University, 23110 Elazig, Turkey. ${ }^{2}$ Department of Pathology, Faculty of Veterinary Medicine, Firat University, Elazig, Turkey. ${ }^{3}$ Department of Virology, Faculty of Veterinary Medicine, Firat University, Elazig, Turkey.

Received: 29 September 2021 Accepted: 27 December 2021

Published online: 12 January 2022

\section{References}

1. Schat KA, Nair V. Marek's disease. In: Swayne DE, Glisson JR, McDougald LR, Nolan LK, Suarez DL, Nair N, editors. Diseases of poultry. Ames: Wiley; 2013. p. 515-52.

2. Davison AJ, Eberle R, Ehlers B, Hayward GS, McGeoch DJ, Minson AC, et al. The order herpesvirales. Arch Virol. 2009;154:171-7.

3. Reddy SM, Izumiya Y, Lupiani B. Marek's disease vaccines: current status, and strategies for improvement and development of vector vaccines. Vet Microbiol. 2017;206:113-20.

4. Witter RL, Calnek BW, Buscaglia C, Gimeno IM, Schat KA. Classification of Marek's disease viruses according to pathotype: philosophy and methodology. Avian Pathol. 2005;34:75-90.

5. Becker Y, Asher Y, Tabor E, Davidson I, Malkinson M, Weisman Y. Polymerase chain reaction for differentiation between pathogenic and nonpathogenic serotype 1 Marek's disease viruses (MDV) and vaccine viruses of MDV-serotypes 2 and 3. JVirol Methods. 1992;40(3):307-22.

6. Madej JP, Wozniakowski G, Gawel A. Morphology of immune organs after very virulent plus strain of Marek's disease virus infection in vaccinated hens. Pol J Vet Sci. 2016;19(2):325-35.

7. Tulman ER, Afonso CL, Lu Z, Zsak L, Rock DL, Kutish GF. The genome of a very virulent Marek's disease virus. J Virol. 2000;74:7980-8.

8. Cui Z, Lee LF, Liu JL, Kung HJ. Structural analysis and transcriptional mapping of the Marek's disease virus gene encoding pp38, an antigen associated with transformed cells. J Virol. 1991;65:6509-15.

9. Liu JL, Kung HJ. Marek's disease herpesvirus transforming protein MEQ: a C-Jun analogue with an alternative life style. Virus Genes. 2000;21:51-64

10. Lee SI, Takagi M, Ohashi K, K, Sugimoto C, Onuma M. Difference in the meq gene between oncogenic and attenuated strains of Marek's disease virus serotype 1. J Vet Med Sci. 2000;62(3):287-92.

11. Bradley G, Hayashı M, Lancz G, Tanaka M, Nonoyama M. Structure of the BamHI-H gene family: genes of putative importance in tumor induction. $J$ Virol. 1989;63:2534-42.

12. Silva RF, Reddy SM, Lupiani B. Expansion of a unique region in the Marek's disease virus genome occurs concomitantly with attenuation but is not sufficient to cause attenuation. J Virol. 2004;2004(78):733-40. 
13. Tian M, Zhao Y, Lin Y, Zou N, Liu C, Liu P, et al. Comparative analysis of oncogenic genes revealed unique evolutionary features of field Marek's disease virus prevalent in recent years in China. Virol J. 2011;15(8):121-32.

14. Bayoumi M, El-Saied M, Ahmed B, El-Mahdy M, Amer H. Gallid alphaherpesvirus 2 in the Egyptian turkeys: molecular characterization and establishment of a universal system for phylogenetic classification. Intervirology. 2021;64(3):156-64.

15. Spatz SJ, Petherbridge L, Zhao Y, Nair V. Comparative full-length sequence analysis of oncogenic and vaccine (Rispens) strains of Marek's disease virus. J Genl Virol. 2007;88(4):1080-96.

16. Zhang F, Liu CJ, Zhang YP, Li ZJ, Liu AL, Yan FH, et al. Comparative fulllength sequence analysis of Marek's disease virus vaccine strain 814. Arch Virol. 2012;157(1):177-83.

17. Shamblin CE, Greene N, Arumugaswami V, Dienglewicz RL, Parcells MS. Comparative analysis of Marek's disease virus (MDV) glycoprotein-, Iytic antigen pp38- and transformation antigen Meq-encoding genes: association of meq mutations with MDVs of high virulence. Vet Microbiol. 2004;102(3-4):147-67.

18. Trimpert J, Groenke N, Jenckel M, He S, Kunec D, Szpara ML, et al. A phylogenomic analysis of Marek's disease virus reveals independent paths to virulence in Eurasia and North America. Evol Appl. 2017;10(10):1091-101.

19. Renz KG, Cooke J, Clarke N, Cheetham BF, Hussain Z, Fakhrul Islam AF, et al. Pathotyping of Australian isolates of Marek's disease virus and association of pathogenicity with meq gene polymorphism. Avian Pathol. 2012;41(2):161-76.

20. Chacón RD, Astolfi-Ferreira CS, Guimarães MB, Torres LN, De La Torre DI, de Sá LRM, et al. Detection and molecular characterization of a natural coinfection of Marek's disease virus and reticuloendotheliosis virus in Brazilian backyard chicken flock. Vet Sci. 2019;6(4):92.

21. López-Osorio S, Piedrahita D, Espinal-Restrepo MA, Ramírez-Nieto GC, Nair V, Williams SM, et al. Molecular characterization of Marek's disease virus in a poultry layer farm from Colombia. Poult Sci. 2017:96(6):1598-608

22. Mescolini G, Lupini C, Davidson I, Massi P, Tosi G, Fiorentini L, et al. Molecular characterization of a Marek's disease virus strain detected in tumour-bearing turkeys. Avian Pathol. 2020;49(2):202-7.

23. Yilmaz A, Turan N, Bayraktar E, Tali HE, Aydin O, Umar S, et al. Molecular characterisation and phylogenetic analysis of Marek's disease virus in Turkish layer chickens. Br Poult Sci. 2020;61(5):523-30.

24. Abayli H, Karabulut B, Ozbek R, Ongor H, Timurkaan N, Tonbak S. Detection and molecular characterization of a highly oncogenic Marek's disease virus from vaccinated hens in Turkey. Acta Virol. 2021;65(2):212-20.

25. Ozan E, Muftuoglu B, Sahindokuyucu I, Kurucay HN, Inal S, Kuruca N, et al. Marek's disease virus in vaccinated poultry flocks in Turkey: its first isolation with molecular characterization. Arch Virol. 2021;166(2):559-69.

26. Pennycott TW, Venugopal K. Outbreak of Marek's disease in a flock of turkeys in Scotland. Vet Rec. 2002;150:277-9.

27. Reddy KBAK, Namratha ML, Kumar YR, Soujanya S, Lakshman M. Marek's disease outbreak among vaccinated flock of broad breasted white Turkey breed. J Entomol Zool Stud. 2019;7(4):876-9.

28. Shehata AA, Lüschow D, Hafez HM. History and current status of Marek's disease in turkeys. Ger J Vet Res. 2021;1(3):1-6.

29. Hauck R, Mays J, Dunn JR, Shivaprasad HL. Two cases of Marek's disease in backyard turkeys. Avian Dis. 2020;64(3):347-51.

30. Ates MB, Celik Z, Ciftci M. Pathological and immunohistochemical examinations on co-infection with coligranulomatosis and Marek's disease in a Turkey flock. J of Poult Res. 2020;17(2):87-95.

31. Blake-Dyke C, Baigent S. Marek's disease in commercial Turkey flocks. Vet Rec. 2013;173:376.

32. Davidson I, Malkinson M, Weisman Y. Marek's disease in turkeys. I. a sevenyear survey of commercial flocks and experimental infection using two field isolates. Avian Dis. 2002;46:314-21.

33. Fabricant CG, Fabricant J, Litrenta MM, Minick CR. Virus-induced atherosclerosis. J Exp Med. 1978;148:335-40.

34. Fabricant CG, Fabricant J. Atherosclerosis induced by infection with Marek's disease herpesvirus in chickens. Am Heart J. 1999;138:465-8.

35. Kawada M, Yanai T, Sakai H, Yoshida K, Yamazoe K, Ishikawa K, et al. Arteriosclerosis associated with a natural Marek's disease infection in a Japanese bantam (Gallus gallus). Avian Pathol. 1995;24:565-71.
36. Gurel A, Arun SS, Kuscu B, Yesildere T. Studies on the diagnosis of spontaneous Marek's disease of chickens by Histopathological and Immunoperoxidase methods. Turk J Vet Anim Sci. 2003;27(4):861-72.

37. Deuchande R, Murphy A, Otter A, Baigent S, Wood A, Irvine RM. Marek's disease in turkeys. Vet Rec. 2012;171(23):602.

38. Woźniakowski G, Samorek-Salamonowicz E, Kozdruń W. Molecular characteristics of polish field strains of Marek's disease herpesvirus isolated from vaccinated chickens. Acta Vet Scand. 2011;53:10.

39. Ongor $\mathrm{H}$, Bulut H. PCR based evidence of reticuloendotheliosis virus infection in chickens from Turkey. Pak Vet J. 2011;31:360-2.

40. Murata S, Chang KS, Lee SI, Konnai S, Onuma M, Ohashi K. Development of a nested polymerase chain reaction method to detect oncogenic Marek's disease virus from feather tips. J Vet Diagn Investig. 2007;19(5):471-8.

41. Kumar S, Stecher G, Li M, Knyaz C, Tamura K. MEGA X: Molecular evolutionary genetics analysis across computing platforms. Mol Biol Evol. 2005;35:1547-9.

42. Tamura K, Nei M. Estimation of the number of nucleotide substitutions in the control region of mitochondrial DNA in humans and chimpanzees. Mol Biol Evol. 1993;10:512-26.

43. Muhire BM, Varsani A, Martin DP. SDT: a virus classification tool based on pairwise sequence alignment and identity calculation. PLoS One. 2014;9:e108277.

\section{Publisher's Note}

Springer Nature remains neutral with regard to jurisdictional claims in published maps and institutional affiliations.

Ready to submit your research? Choose BMC and benefit from

- fast, convenient online submission

- thorough peer review by experienced researchers in your field

- rapid publication on acceptance

- support for research data, including large and complex data types

- gold Open Access which fosters wider collaboration and increased citations

- maximum visibility for your research: over $100 \mathrm{M}$ website views per year

At BMC, research is always in progress.

Learn more biomedcentral.com/submissions 